\title{
TYRPI mRNA expression in melanoma metastases correlates with clinical outcome
}

\author{
F Journe', H Id Boufker', L Van Kempen ${ }^{2,7}$, M-D Galibert ${ }^{3}$, M Wiedig', F Salès', A Theunis ${ }^{4}$, D Nonclercq ${ }^{5}$, \\ A Frau ${ }^{5}$, G Laurent $^{5}$, A Awada ${ }^{6}$ and G Ghanem*,I \\ 'Laboratoire d'Oncologie et de Chirurgie Expérimentale, Institut Jules Bordet, Université Libre de Bruxelles, I rue Heger-Bordet, B I 000, Brussels, Belgium; \\ ${ }^{2}$ Department of Pathology, Radboud University Nijmegen Medical Centre, Nijmegen, The Netherlands; ${ }^{3}$ CNRS UMR 606I, Institut de Génétique et \\ Développement de Rennes, Rennes, France; ${ }^{4}$ Département de Pathologie, Institut Jules Bordet, Université Libre de Bruxelles, Brussels, Belgium; ${ }^{5}$ Service \\ d'Histologie, Université de Mons, Mons, Belgium; ${ }^{6}$ Clinique d'Oncologie Médicale, Institut Jules Bordet, Université Libre de Bruxelles, Brussels, Belgium
}

BACKGROUND: Clinical outcome of patients with high-risk melanoma cannot be reliably predicted on the basis of classical histopathological examination. Our study aimed to determine in melanoma metastases a gene expression profile associated with patient survival, and to identify and validate marker(s) of poor clinical outcome.

METHODS: Skin and lymph node metastases from melanoma patients (training population) were used to identify candidate prognostic marker(s) based on DNA microarray analysis. Additional skin metastases (validation population) were used to assess the prognostic value of the first ranked gene by real-time PCR.

RESULTS: We performed microarray analysis in the training population and generated a list of 278 probe sets associated with a shorter survival. We used the first ranked gene, tyrosinase-related protein I (TYRPI), further measured its expression in the validation population by real-time PCR and found it to be significantly correlated with distant metastasis-free survival (DMFS), overall survival (OS) and Breslow thickness. We also found that it was fairly well conserved in the course of the disease regardless of the delay to metastasis occurrence. Finally, although Tyrp I protein (immunohistochemistry (IHC)) was only detected in about half of the samples, we showed that its expression also correlated with Breslow thickness.

CONCLUSION: Our data indicate that TYRPI mRNA expression level, at least in skin metastases, is a prognostic marker for melanoma, and is particularly useful when prognostic pathology parameters at the primary lesion are lacking. Its conserved expression further supports its use as a target for therapy.

British Journal of Cancer (201 I) I 05, 1726-1732. doi:10.1038/bjc.201 I.45 I www.bjcancer.com

Published online I November 201।

(c) 201 I Cancer Research UK

Keywords: melanoma; prognosis; marker; Breslow; survival

The prognosis of melanoma is based on the histopathological criteria described in the American Joint Committee on Cancer (AJCC) melanoma staging system. These include the Breslow index, mitotic rate, ulceration status and extent of lymph node involvement (Balch et al, 2009). Despite this staging system, the clinical behaviour of melanoma is often unpredictable (Nagore et al, 2005), because melanoma is a group of diseases with various biological subtypes (Lomas et al, 2008). In addition, patients with melanoma metastatic to the skin show variable survival: some may survive for a long time, whereas some die of disseminated disease within 1 year of removal of skin metastases (Hofmann-Wellenhof et al, 1996).

Studies based on melanoma gene expression profiling have been performed in order to improve the prognosis of the disease and to predict its response to treatment (Hoek, 2007). First, a comparison of gene expression profiles of normal skin, nevi and primary and

\footnotetext{
*Correspondence: Dr G Ghanem; E-mail: gghanem@ulb.ac.be

${ }^{7}$ Current address: Department of Pathology, McGill University/Jewish General Hospital, Montreal, Quebec, Canada.

Received 4 May 2011; revised 3 October 2011; accepted 5 October 20I I; published online I November 201 |
}

metastatic melanomas has identified 2602 signature genes that could be used to distinguish two metastatic patterns, which are already emergent in large primaries (Haqq et al, 2005). Second, cDNA expression microarray in primary melanoma has revealed a signature of 254 genes characterising patients at risk of developing distant metastases (Winnepenninckx et al, 2006). Third, highthroughput gene microarray in metastatic melanoma has determined a set of 80 probes (70 genes) associated with survival (Mandruzzato et al, 2006). Finally, molecular profiling of lymph node metastases of stage III melanoma patients has disclosed 21 genes whose expression levels correlated with clinical outcome (John et al, 2008). Thus, several new marker genes have shown promise, and large-scale studies are now warranted to clinically validate them for the development of new prognostic tools, diagnostic approaches and biological-targeted therapies (Larson et al, 2009).

Such gene discovery platforms may help to identify new molecular markers in melanoma metastases, enabling one to refine the prognosis at the time of tumour progression, especially in thin melanomas. They may also help to establish a prognosis in patients with unknown melanoma primaries $(2-6 \%$ of all melanoma cases) (Schlagenhauff et al, 1997). The identification of such markers in high-risk melanoma patients would be 
important for the design and the interpretation of clinical trials, and could be of great benefit as one might also foresee the development of useful and effective adjuvant therapies.

This work describes a gene profiling study in skin and lymph nodes, which are the most frequent melanoma metastases, that shows an inverse correlation between tyrosinase-related protein 1 (TYRP1) expression level and patient overall survival. A validation study using quantitative PCR only in skin metastases further supports TYRP1 as a new marker of poor clinical outcome.

\section{MATERIALS AND METHODS}

\section{Patients and tissue collection}

Skin and lymph node metastases were collected from patients with stage III melanoma undergoing surgery at Institut Jules Bordet. Samples (mean size $10 \mathrm{~mm}$, no necrosis) were collected randomly with no inclusion or exclusion criteria. Half of each biopsy was fixed in formalin, embedded in paraffin, sectioned according to routine clinical procedures and was used for immunohistochemistry. The other half was snap-frozen in liquid nitrogen and stored at $-80^{\circ} \mathrm{C}$, and was dedicated to microarray analysis and real-time PCR. Microdissection has been carried out by one surgeon (FS) on each sample before any snap freezing. This study was approved by the ethic committee of Institut Jules Bordet and performed in accordance with the REMARK guidelines (Alonzo, 2005; McShane et al, 2005). The clinical characteristics of the patients are outlined in Table 1.

\section{RNA extraction}

Frozen samples were homogenised using the FastPrep-24 homogeniser system with lysing matrix D (MP Biomedicals, Illkirch Cedex, France) in RLT buffer supplemented with $\beta$-mercaptoethanol (RNeasy Mini Kit, Qiagen, Venlo, The Netherlands) at $4{ }^{\circ} \mathrm{C}$. Centrifugation with RNeasy spin column separated melanin from the total RNA. After washing steps, RNA was collected in RNasefree water and RNA concentrations were evaluated using a NanoDropTM 1000 spectrophotometer (Thermo Scientific, Wilmington, DE, USA). RNA quality of each sample was assessed based on the RNA profile generated by the bioanalyzer (Agilent Technologies, Santa Clara, CA, USA).

\section{Microarray analysis}

Gene expression profiling was performed with the training population using the Affymetrix technology (Affymetrix, Inc.,

Table I Characteristics of metastasis samples from melanoma patients

\begin{tabular}{|c|c|c|}
\hline & $\begin{array}{c}\text { Training } \\
\text { population }\end{array}$ & $\begin{array}{l}\text { Validation } \\
\text { population }\end{array}$ \\
\hline Number of samples & 32 & 89 \\
\hline $\begin{array}{l}\text { Type of metastasis } \\
\text { Skin } \\
\text { Lymph node }\end{array}$ & $\begin{array}{l}13 \\
19\end{array}$ & $\begin{array}{r}89 \\
0\end{array}$ \\
\hline $\begin{array}{l}\text { Gender } \\
\text { Male } \\
\text { Female }\end{array}$ & $\begin{array}{l}15 \\
17\end{array}$ & $\begin{array}{l}35 \\
54\end{array}$ \\
\hline $\begin{array}{l}\text { Median age (range), years } \\
\text { Median Breslow (range), } \text { mm }^{\mathrm{b}} \\
\text { Median DMFS (range), months } \\
\text { Median OS (range), months }\end{array}$ & $\begin{array}{c}49(26-88) \\
2.0(0.9-9.1) \\
14(0-105) \\
49(8-186)\end{array}$ & $\begin{array}{l}58(20-88) \\
3.2(0.3-15) \\
9(0-293) \\
45(6-334)\end{array}$ \\
\hline
\end{tabular}

Abbreviations: DMFS = distant metastasis-free survival; OS = overall survival. ${ }^{\text {a }} \mathrm{Age}$ at the diagnosis of primary melanoma. 'Breslow is the thickness of primary tumours as determined by histopathological examination.
Santa Clara, CA, USA). RNA was hybridised on Human Genome U133 Plus 2.0 Array. The scanning of the chips was done according to standard Affymetrix protocols. Image analysis and probe quantification were performed with the Affymetrix software that produced raw probe intensity data in the Affymetrix CEL files. Before statistical analysis, data were loaded and normalised (RMA program) using the software package BRB Array Tools (http:// linus.nci.nih.gov/BRB-ArrayTools.html). A class comparison was performed between groups of arrays based on patient survival (group $1(N=10)$ : overall survival $(\mathrm{OS})<30$ months; group 2 $(N=22)$ : OS $\geqslant 30$ months) sorting probe sets passing filtering criteria (significant at 0.05 level of the univariate two-sample $t$-test and fold change strictly $>2.5$ ). To assess a possible bias due to a difference in tumour burden, the expression of the specific melanocyte marker S100B was compared between both groups.

\section{Real-time PCR}

The TYRP1 mRNA expression was quantified by real-time PCR. cDNA was synthesised using a standard reverse transcription method (qScript cDNA SuperMix, Quanta Biosciences, Gaithersburg, MD, USA). Real-time PCR reactions were performed using the SYBR Green PCR Master Mix (Applied Biosystems, Foster City, CA, USA) and sequence-specific primer sets for TYRP1 (forward = $5^{\prime}$-CCGAAACACAGTGGAAGGTT- ${ }^{\prime}$, reverse $=5^{\prime}$-TCTGTGAAGG TGTGCAGGA- $3^{\prime}$ ), for S100B (forward $=5^{\prime}$-ATTCTGGAAGGGAGG GAGAC- $3^{\prime}$, reverse $=5^{\prime}$-CGTGGCAGGCAGTAGTAACC- $3^{\prime}$ ) and for $\beta$-actin $\quad\left(\right.$ forward $=5^{\prime}$-CTGGCACCCAGCACAATG- $3^{\prime}$, reverse $=$ $5^{\prime}$-CCGATCCACACGGAGTACTTG-3') (Sigma-Genosys, Pampisford Cambs, UK). The amplification was performed on an ABI PRISM 7900HT Sequence Detection System (Applied Biosystems) using 40 cycles of a two-step PCR $\left(15 \mathrm{~s}\right.$ at $95^{\circ} \mathrm{C}$ and $60 \mathrm{~s}$ at $\left.60^{\circ} \mathrm{C}\right)$ after an initial activation step $\left(95^{\circ} \mathrm{C}\right.$ for $\left.10 \mathrm{~min}\right)$. Melting curves from $60{ }^{\circ} \mathrm{C}$ to $99^{\circ} \mathrm{C}$ were assessed to evaluate PCR specificity. Serial dilutions of purified amplicons were utilised to generate standard melting curves. The mRNA expressions of TYRP1 and S100B were normalised to $\beta$-actin (loading control). The S100B is one of the most reliable biomarkers for melanoma and it is commonly used as a marker for tumour load.

\section{Immunohistochemistry}

For Tyrp1 immunostaining, dewaxed tissue sections were rehydrated in distilled water, incubated for $1 \mathrm{~h}$ in distilled water at $85^{\circ} \mathrm{C}$, and exposed for $5 \mathrm{~min}$ to $0.5 \% \mathrm{H}_{2} \mathrm{O}_{2}$. Thereafter, the sections were rinsed in phosphate-buffered saline (PBS), incubated for $15 \mathrm{~min}$ in PBS containing $0.5 \%$ casein, and then exposed for $1 \mathrm{~h}$ to a primary antibody raised against the carboxyterminal end of Tyrp1 protein (mouse monoclonal anti-Tyrp1, dilution $1: 50$, clone G3E6; Abcam, Cambridge, UK), and for additional $30 \mathrm{~min}$ to a secondary antibody raised against mouse immunoglobulins and conjugated with horseradish peroxidase (HRP-conjugated goat polyclonal anti-mouse IgG, dilution 1:50; Abcam). Bound peroxidase activity was visualised by incubation in the presence of $\mathrm{H}_{2} \mathrm{O}_{2}$ and 3-amino-9-ethylcarbazole (AEC substrate) (Vector Laboratories, Burlingame, CA, USA). The sections were counterstained with hemalun, mounted using an aqueous-based medium (Vectamount AQ, Vector), and analysed as described in Figure 3.

\section{Statistical analysis}

For statistical analyses of microarray and real-time PCR data, intensity values were log-transformed to a base- 2 scale. False discovery rate (FDR) was determined using the software BRB Array Tools. Statistical correlation between two variables was assessed using Spearman's rho test. Statistical significance between two independent groups was examined using the Mann-Whitney test. Variations of TYRP1 expression during time in different 
patients were tested by Kruskal-Wallis test. Distant metastasis-free survival (DMFS) and OS were estimated using the Kaplan-Meier method. Univariate analyses of relapse/death were performed using Cox's proportional hazards method. Significance of the positive predictive value was determined by Fisher's exact test. The $P$-values of $<0.05$ were considered as statistically significant. All statistical analyses were performed using SPSS 15.0 Inc. (Chicago, IL, USA).

\section{RESULTS}

\section{Characteristics of melanoma patients}

The characteristics of the training and the validation populations are in Table 1. A large majority of patients (95\%) had primary melanoma with a Breslow thickness $>1 \mathrm{~mm}$ and thus an unfavourable prognosis (however, 5 patients in the validation population had tumours with $<1 \mathrm{~mm}$ thickness). In the training population, all patients deceased, whereas in the validation population some patients were lost for follow-up (6 out of 89 ) or were still alive (10 out of 89 ) over a period of up to 25 years.

\section{Identification of genes related to survival in the training population}

The training population was subjected to microarray analysis as described in the Materials and Methods. A class comparison between two groups of samples from patients with different survival sorted 278 probe sets passing filtering criteria (Supplementary Table 1). The first ranked gene was TYRP1 (fold change $=33.9, P=0.00004)$, which actually codes for an enzyme involved in melanogenesis, a unique feature restricted to melanocytes. Interestingly, among the other highly ranked upregulated probe sets, five genes were also associated with the pigmentation (SILV, DCT, OCA2, TYR and MITF; Table 2), suggesting that many melanogenesis markers could be associated with shorter survival. A possible bias due to a difference in tumour burden was checked using S100B, and data showed that the latter marker did not differ significantly between the two groups (Table 2, Control). The TYRP1 was then chosen to be further evaluated as a new potential marker of poorer prognosis.

\section{Comparison of probe set signature and TYRP1 mRNA in the training population}

In order to determine if TYRP1 mRNA expression genuinely reflected the 278 probe set signature, scores of the signature and TYRP1 were calculated as follows: the score of probe set signature was the mean expression levels (log-transformed values) of upregulated genes minus the mean expression levels (log-transformed values) of downregulated genes, and the score of TYRP1 was the log-transformed value. First, there were significant correlations between the score of the probe set signature and the score of TYRP1 $(\rho=0.719, P<0.001$, Spearman's rho). Second, TYRP1 mRNA expression was significantly higher $(P<0.001$, Mann-Whitney test) in the subpopulation of patients with poor prognosis (group 1). Hence, TYRP1 mRNA expression was actually as informative as the probe set signature with respect to patient survival.

\section{Validation of TYRP1 microarray data by real-time PCR}

Training population Microarray data were validated by real-time PCR measurement of TYRP1 mRNA expression in the skin metastases $(N=13)$ of the training population. We validated the microarray data on skin metastases only in order to match with the validation population. Results showed a significant correlation between microarray and PCR data $(\rho=0.780, P=0.002$, Spearman's rho). Accordingly, TYRP1 mRNA expression (real-time PCR) was significantly higher $(P=0.001$, Mann - Whitney test $)$ in group 1 (OS $<30$ months) when compared with group 2 (OS $\geqslant 30$ months).

Validation population The expression of TYRP1 mRNA was evaluated by real-time PCR in an independent cohort of skin metastases $(N=89$, Table 1 , validation population). The population was divided into quartiles on the basis of TYRP1 levels and subgroups were subjected to Kaplan-Meier analysis. The quartile corresponding to the lowest TYRP1 levels presented a better survival when compared with the three other quartiles (higher TYRP1 levels), for which the Kaplan-Meier curves were not significantly different (DMFS $P=0.221$, OS $P=0.112$, Cox regression). Therefore, a cutoff point at the first quartile was set in order to divide the population in two groups of 'low' and 'high' TYRP1 mRNA levels. Hence, in the validation population, high TYRP1 mRNA expression was significantly associated with a shorter DMFS and a shorter OS (Figure 1). A possible difference in tumour burden between the two groups was checked by real-time PCR of S100B and the analysis did not reveal significant difference $(P=0.91$; Mann-Whitney). Accordingly, we found a very good correlation between TYRP1/ $\beta$-actin and TYRP1/S100B ratios ( $\rho=0.770, P<0.001$, Spearman's rho), indicating that S100B and $\beta$-actin changes are closely related, and further supporting no significant difference in tumour load.

\section{Serial measurements of TYRP1 expression in recurrent skin metastases of the same patient}

As the data suggest that TYRP1 mRNA expression in skin metastases has prognostic value regardless of the time of their

Table 2 Ranking of the pigmentation-related genes included in the 278 probe set signature associated with a poorer survival

\begin{tabular}{|c|c|c|c|c|c|c|c|c|}
\hline Rank $^{\mathbf{a}}$ & $P$-value ${ }^{b}$ & FDR & $\begin{array}{l}\text { Geom. mean of } \\
\text { intensities in OS } \\
<30 \text { months }\end{array}$ & $\begin{array}{l}\text { Geom. mean of } \\
\text { intensities in OS } \\
>30 \text { months }\end{array}$ & $\begin{array}{l}\text { Fold } \\
\text { change }\end{array}$ & Probe set & $\begin{array}{l}\text { Gene } \\
\text { symbol }\end{array}$ & Description \\
\hline । & 0.00004 & 0.15 & 687.4 & 20.3 & 33.9 & 205694_at & TYRPI & Tyrosinase-related protein 1 \\
\hline 4 & 0.00103 & 0.20 & 1291.6 & 97.0 & 13.3 & 205338_s_at & DCT & $\begin{array}{l}\text { Dopachrome tautomerase } \\
\text { (tyrosine-related protein 2) }\end{array}$ \\
\hline 13 & 0.00174 & 0.21 & 145.3 & 18.0 & 8.1 & 206498_at & OCA2 & Oculocutaneous albinism II \\
\hline Control $^{c}$ & 0.649 & - & 929.0 & | 145.2 & 0.8 & 209686_at & SIOOB & S100 calcium binding protein B \\
\hline
\end{tabular}

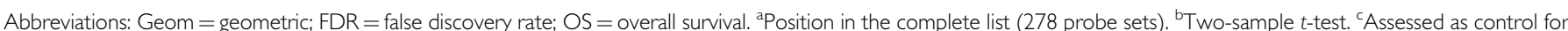
difference in tumour load. 

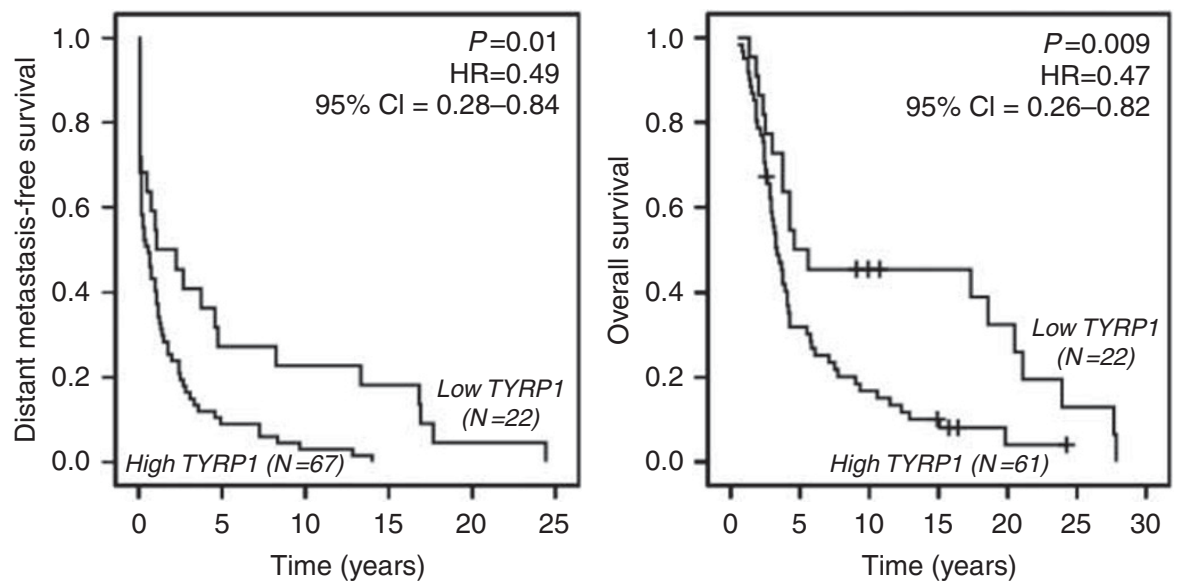

Figure I The TYRPI mRNA expression and survival of 89 patients with melanoma skin metastases. The distant metastasis-free survival and the overall survival curves (Kaplan-Meier analysis) were determined for patients of the validation population. Patients were distributed according to the TYRPI mRNA levels (real-time PCR determination) as defined in the 'Results'. Cox regressions were calculated to determine P-values, hazard ratios (HRs) and $95 \%$ confidence intervals $(\mathrm{Cls})$. The symbol ' + ' indicates the patients who were alive at the time of analysis. The mRNA expression of TYRPI had a positive predictive value of $94 \%(P=0.0$ I, Fisher's exact test) for a shorter DMFS ( $<7.5$ years) and a positive predictive value of $96 \%(P<0.00$ I) for a shorter OS $(<15$ years $)$

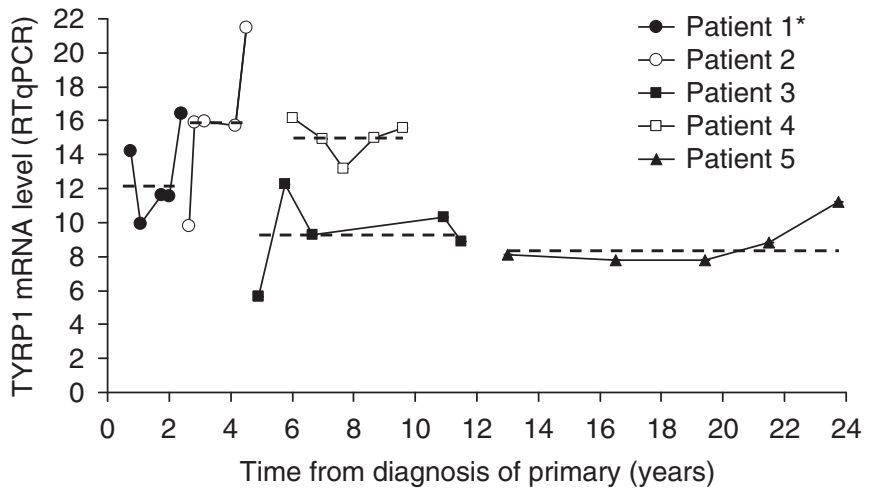

Figure 2 Variation of TYRPI mRNA expression levels over time in recurrent skin metastases within the same patient. The levels of expression of TYRPI mRNA were evaluated in quadruplicate by real-time PCR in five different melanoma skin metastases obtained over years from each of five patients. The TYRPI mRNA levels (median) are plotted against time from diagnosis of primary. Dashed line indicates the median value of TYRPI mRNA expression for each patient. For each patient, TYRPI mRNA levels were compared using Kruskal-Wallis test ( ${ }^{\star}$ significant). A weak significant difference was calculated in patient I $(P=0.03)$.

development (median: 30 months, range: 1-332), it was measured in five consecutive metastases resected from each of five patients (Figure 2). The mRNA levels of TYRP1 remained within a narrow range with a coefficient of variation of $<16 \%$ for each patient.

\section{Evaluation of Tyrp1 protein expression in skin metastases}

The expression of the protein (Tyrp1/gp75) was examined by immunohistochemistry (IHC) in a panel of paraffin-embedded biopsies from the skin metastases of the validation population $(N=52$; Figure 3$)$. The Tyrp1 protein immunoreactivity was apparent only in $48 \%$ of cases positive for TYRP1 mRNA expression. However, in samples with positive staining, there was a significant correlation between staining scores and mRNA levels (real-time PCR) $(\rho=0.488, P=0.034$, Spearman's rho).

\section{Correlation between TYRP1 mRNA or Tyrp1 protein and prognostic parameters at primary}

The expressions of TYRP1 mRNA and Tyrp1 protein in skin metastases were correlated with the AJCC prognostic parameters at diagnosis (Table 3). Both TYRP1 mRNA and Tyrp1 protein expressions significantly correlated with Breslow thickness. Nonsignificant trends were recorded between Tyrp1 protein and the ulceration status or the number of positive lymph nodes. Thus, TYRP1 mRNA and Tyrp1 protein expressions in cutaneous melanoma metastases remain associated with prognostic features of the corresponding primary lesions, regardless of the interval between the diagnosis of the primary and the occurrence of the cutaneous metastases.

\section{DISCUSSION}

First, 278 probe sets associated with a short survival of patients with melanoma metastases have been identified by microarray analysis in skin and lymph node metastases. The TYRP1 expression ranked first and, alone, was predictive for DMFS and OS as validated in skin metastases, with the skin being the first site of recurrence ( $56 \%$ of all patients) (Savoia et al, 2009). The TYRP1 also significantly correlated with Breslow thickness, which is the most accurate prognostic parameter of the corresponding primary lesion, and thus brings information that is quite different, although complementary, from the 'mitotic index' that is calculated at the time of metastasis itself (Bogunovic et al, 2009).

We ruled out any possible bias due to variation in tumour burden between the compared groups in both the training and validation populations by analysing the specific melanocyte marker S100B; the latter showed no difference in expression. Moreover, as TYRP1 gene is related to pigmentation and is exclusively expressed in melanocytes and melanoma cells, the documented changes in its expression is restricted to tumour tissues.

Corroborating our results, a previous study reported that the repression of TYRP1 is concomitant to the induction of an isoform of the microtubule-associated protein 2 (MAP-2), a marker of immature neurons (Fang et al, 2001), and that patients with MAP2-positive (hence, low TYRP1) primary melanomas have a significantly improved survival (Soltani et al, 2005). 

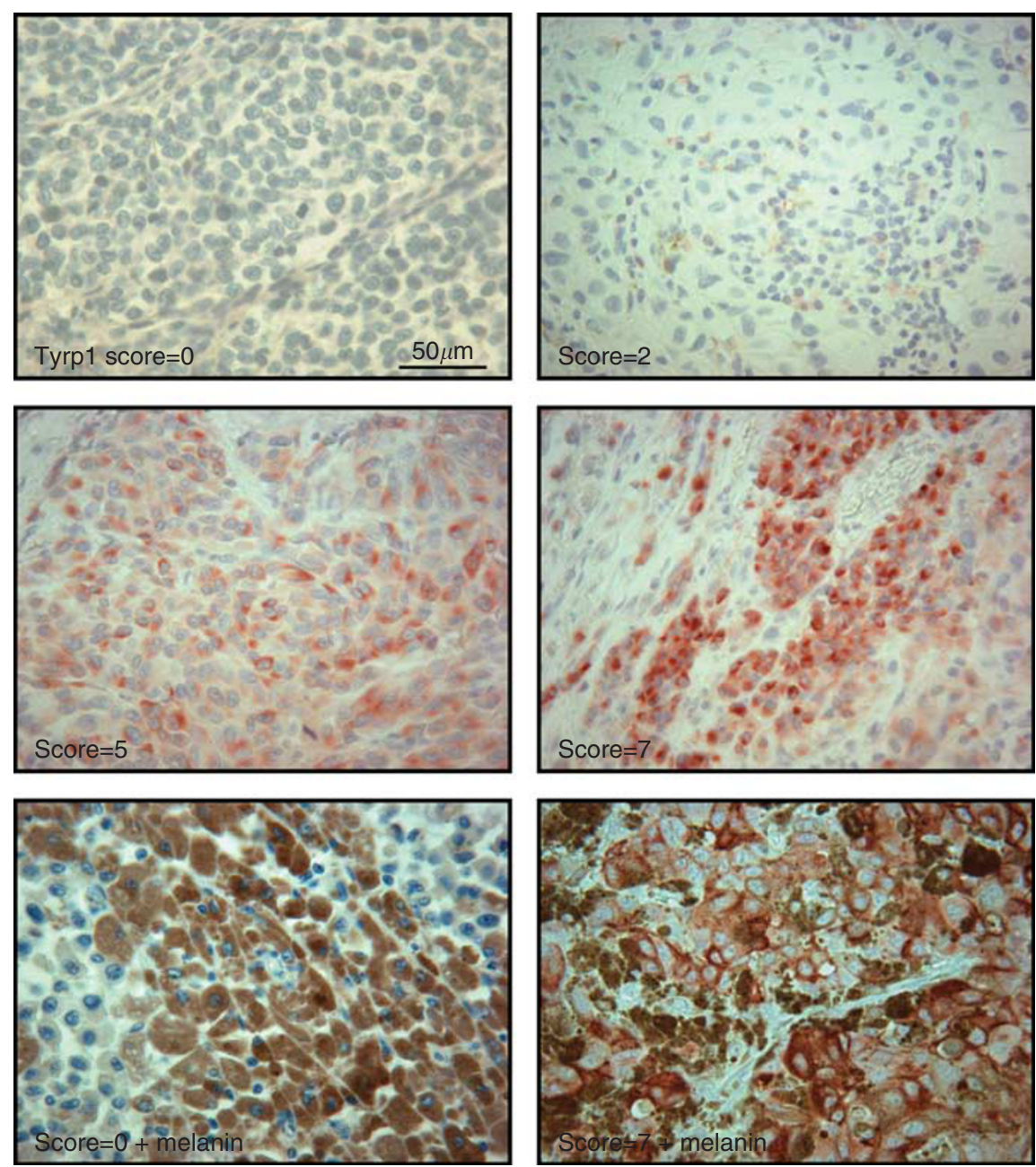

Figure 3 Representative micrographs of Tyrpl protein expression in paraffin-embedded specimens of melanoma skin metastasis. The expression of Tyrp I protein was evaluated by immunohistochemistry in 52 amelanotic or pigmented samples. A score from 0 to 8 was calculated by adding a score reflecting the proportion of positively stained cells (none $=0 ;<I / \mid 00=1 ; 1 / 100$ to $|/| 10=2 ;|/| 0$ to $|/ 3=3 ;| / 3$ to $2 / 3=4 ;$ and $>2 / 3=5$ ) to a score reflecting the staining intensity (none $=0 ;$ weak $=1$; intermediate $=2$; and strong $=3$ ). Cytoplasmic red staining was considered as positive. Brown granules represent melanin pigment.

Table 3 Association of TYRPI/Tyrp I mRNA/protein expression with pathological parameters of primaries

\begin{tabular}{lcc}
\hline & TYRPI mRNA & Tyrpl protein \\
\hline Breslow $^{\mathrm{a}}$ & 87 & \\
$N$ & 0.281 & 41 \\
$\rho$ & $\mathbf{0 . 0 0 8}$ & 0.383 \\
$P$ & & $\mathbf{0 . 0 1 3}$ \\
Lymph nodes $^{\mathrm{a}, \mathrm{b}}$ & 88 & \\
$N$ & 0.095 & 45 \\
$\rho$ & 0.377 & 0.289 \\
$P$ & 87 & 0.054 \\
Ulceration (no/yes) $^{c}$ & 0.368 & 41 \\
$N$ & & 0.056 \\
$P$ & &
\end{tabular}

Abbreviation: TYRP I = tyrosinase-related protein $1 .{ }^{\text {a C}}$ Correlation test (Spearman's rho). ${ }^{b}$ Number of positive lymph nodes at primary. 'Nonparametric test (MannWhitney). Bold numbers indicate significant $P$-values.

Importantly, TYRP1 sorted together with five other melanogenesis-related genes (SILV, DCT, OCA2, TYR and MITF), which were also contained in the probe set signature, point to an active pigmentation process. In this context, a previous study using cDNA microarray analysis showed that high expression of DCT/ TYRP2 in metastatic melanoma was associated with a shorter patient survival (Mandruzzato et al, 2006). The question is why would a melanocyte differentiation marker, such as TYRP1, be associated with survival? The hallmark of differentiated melanocytes is an active pigmentation process that may increase with tumour burden. In addition, as melanoma cells are coupling proliferation and differentiation through MITF (Wellbrock et al, 2008), the transcription factor that control the synthesis of $T Y R$, TYRP1 and DCT genes (Murisier and Beermann, 2006), we may reasonably assume that high level of expression of genes involved in melanogenesis results from a net balance of the MITF activity.

Besides the possible role of human Tyrp1 as a melanogenic enzyme (Hearing et al, 1992), several observations provide evidence supporting its putative implication in cell survival. First, Tyrp1 mutation or decrease in expression interferes with melanosome maturation in mouse melanocytes and, most interestingly, attenuates cell proliferation, without evidence of necrosis or apoptosis (Sarangarajan et al, 2000). Second, both Tyrp1 and Dct/Tyrp2 protect the melanocyte against the cytotoxicity of toxic melanin intermediates produced by tyrosinase, without affecting tyrosinase expression or its activity $(\operatorname{Rad}$ et al, 2004). 
The discrepancies between TYRP1 mRNA levels (frozen tissue samples) and Tyrp1/gp75 protein expression (corresponding paraffin embedded samples) that we found in skin metastases of about half of the patients, including some with high TYRP1 mRNA expression but no protein if any, may suggest possible posttranscriptional and/or post-translational events altering the protein recognition by the antibody despite the best choice of the G3E6 antibody that recognises the unglycosylated C-terminus of the protein. Our finding of this discrepancy as well as the use of various anti-Tyrp 1 antibodies in previous studies could explain the previously reported lack of association between Tyrpl protein expression and disease-free or OS (Bolander et al, 2008), and the absence of Tyrp1 protein in the vertical/invasive growth phase of primary lesion (Fang et al, 2001). Furthermore, no or low expression of Tyrp1 protein might be explained by (1) the absence of a putative Tyrp1 chaperone, such as calnexin, which is required to stabilise the protein (Jimbow et al, 1997), (2) a defect in PI3Kdependent Tyrp1 maturation and trafficking to melanosomes (Chen et al, 2001), and/or (3) a loss of Rab proteins, such as Rab38/ 32 , which are involved in the stability of melanogenic enzymes (Wasmeier et al, 2006).

On the other hand, as the activation of melanogenesis enzymes may lead to visible pigmentation, the latter was checked in the same IHC slides, but no correlation was found with Tyrp1 protein expression (example in Figure 3). This finding is consistent with previous studies showing that Tyrp1 can be regulated independently of tyrosinase and pigmentation in mature melanocytes (Vijayasaradhi et al, 1995) and that tyrosinase mRNA or protein expression does not always correlate with pigmentation (Watabe et al, 2004).

Finally, our findings of an association between high TYRP1/ Tyrp1 levels and shorter patient survival, together with a conserved TYRP1 expression throughout the course of the disease, are in line with previous clinical studies that identified circulating anti-Tyrp1 autoantibodies in melanoma patients (Mattes et al, 1983) and that demonstrated melanoma rejection and higher survival in mice treated with a mouse monoclonal antibody against Tyrp1 (Takechi et al, 1996), and support the recent clinical development of a new human anti-Tyrp1 monoclonal antibody for melanoma immunotherapy (Patel et al, 2007) (http://clinicaltrials.gov/ct2/show/NCT01137006).

In conclusion, we found that TYRP1 gene expression level in melanoma skin metastases correlates with both DMFS and OS and with Breslow thickness. Thus, TYRP1 could emerge as a valuable prognostic marker, especially in melanoma patients where important prognostic factors at diagnosis cannot be evaluated (namely unknown or ulcerated primaries) and in metastases of thin melanomas. Our observation of a fairly conserved TYRP1 expression during disease progression further supports its use as a target for antimelanoma therapy.

\section{ACKNOWLEDGEMENTS}

This study received financial support from 'Fondation Medic' and 'Les Amis de l'Institut Bordet'. Hichame Id Boufker is the recipient of a fellowship from the National Fund for Scientific Research (Belgium). Guy Laurent is Senior Research Associate of the National Fund for Scientific Research (Belgium) and the recipient of a grant from the Belgian Fund for Medical Scientific Research. We thank Françoise Coulon for her skilful technical assistance.

Supplementary Information accompanies the paper on British Journal of Cancer website (http://www.nature.com/bjc)

\section{REFERENCES}

Alonzo TA (2005) Standards for reporting prognostic tumor marker studies. J Clin Oncol 23: $9053-9054$

Balch CM, Gershenwald JE, Soong SJ, Thompson JF, Atkins MB, Byrd DR, Buzaid AC, Cochran AJ, Coit DG, Ding S, Eggermont AM, Flaherty KT, Gimotty PA, Kirkwood JM, McMasters KM, Mihm Jr MC, Morton DL, Ross MI, Sober AJ, Sondak VK (2009) Final version of 2009 AJCC melanoma staging and classification. J Clin Oncol 27: 6199-6206

Bogunovic D, O’Neill DW, Belitskaya-Levy I, Vacic V, Yu YL, Adams S, Darvishian F, Berman R, Shapiro R, Pavlick AC, Lonardi S, Zavadil J, Osman I, Bhardwaj N (2009) Immune profile and mitotic index of metastatic melanoma lesions enhance clinical staging in predicting patient survival. Proc Natl Acad Sci U S A 106: 20429-20434

Bolander A, Agnarsdottir M, Stromberg S, Ponten F, Hesselius P, Uhlen M, Bergqvist M (2008) The protein expression of TRP-1 and galectin-1 in cutaneous malignant melanomas. Cancer Genomics Proteomics 5: 293-300

Chen H, Salopek TG, Jimbow K (2001) The role of phosphoinositide 3-kinase in the sorting and transport of newly synthesized tyrosinaserelated protein-1 (TRP-1). J Investig Dermatol Symp Proc 6: 105-114

Fang D, Hallman J, Sangha N, Kute TE, Hammarback JA, White WL, Setaluri V (2001) Expression of microtubule-associated protein 2 in benign and malignant melanocytes: implications for differentiation and progression of cutaneous melanoma. Am J Pathol 158: 2107-2115

Haqq C, Nosrati M, Sudilovsky D, Crothers J, Khodabakhsh D, Pulliam BL, Federman S, Miller 3rd JR, Allen RE, Singer MI, Leong SP, Ljung BM, Sagebiel RW, Kashani-Sabet M (2005) The gene expression signatures of melanoma progression. Proc Natl Acad Sci USA 102: 6092-6097

Hearing VJ, Tsukamoto K, Urabe K, Kameyama K, Montague PM, Jackson IJ (1992) Functional properties of cloned melanogenic proteins. Pigment Cell Res 5: 264-270

Hoek KS (2007) DNA microarray analyses of melanoma gene expression: a decade in the mines. Pigment Cell Res 20: 466-484

Hofmann-Wellenhof R, Woltsche-Kahr I, Smolle J, Kerl H (1996) Clinical and histological features of poor prognosis in cutaneous metastatic melanomas. J Cutan Pathol 23: 199-204
Jimbow K, Gomez PF, Toyofuku K, Chang D, Miura S, Tsujiya H, Park JS (1997) Biological role of tyrosinase related protein and its biosynthesis and transport from TGN to stage I melanosome, late endosome, through gene transfection study. Pigment Cell Res 10: 206-213

John T, Black MA, Toro TT, Leader D, Gedye CA, Davis ID, Guilford PJ, Cebon JS (2008) Predicting clinical outcome through molecular profiling in stage III melanoma. Clin Cancer Res 14: 5173-5180

Larson AR, Konat E, Alani RM (2009) Melanoma biomarkers: current status and vision for the future. Nat Clin Pract Oncol 6: 105-117

Lomas J, Martin-Duque P, Pons M, Quintanilla M (2008) The genetics of malignant melanoma. Front Biosci 13: $5071-5093$

Mandruzzato S, Callegaro A, Turcatel G, Francescato S, Montesco MC, Chiarion-Sileni V, Mocellin S, Rossi CR, Bicciato S, Wang E, Marincola FM, Zanovello P (2006) A gene expression signature associated with survival in metastatic melanoma. J Transl Med 4: 50

Mattes MJ, Thomson TM, Old LJ, Lloyd KO (1983) A pigmentationassociated, differentiation antigen of human melanoma defined by a precipitating antibody in human serum. Int J Cancer 32: 717-721

McShane LM, Altman DG, Sauerbrei W, Taube SE, Gion M, Clark GM (2005) Reporting recommendations for tumor marker prognostic studies. J Clin Oncol 23: $9067-9072$

Murisier F, Beermann F (2006) Genetics of pigment cells: lessons from the tyrosinase gene family. Histol Histopathol 21: 567-578

Nagore E, Oliver V, Botella-Estrada R, Moreno-Picot S, Insa A, Fortea JM (2005) Prognostic factors in localized invasive cutaneous melanoma: high value of mitotic rate, vascular invasion and microscopic satellitosis. Melanoma Res 15: $169-177$

Patel D, Balderes P, Lahiji A, Melchior M, Ng S, Bassi R, Wu Y, Griffith H, Jimenez X, Ludwig DL, Hicklin DJ, Kang X (2007) Generation and characterization of a therapeutic human antibody to melanoma antigen TYRP1. Hum Antibodies 16: $127-136$

Rad HH, Yamashita T, Jin HY, Hirosaki K, Wakamatsu K, Ito S, Jimbow K (2004) Tyrosinase-related proteins suppress tyrosinase-mediated cell death of melanocytes and melanoma cells. Exp Cell Res 298: 317-328 
TYRPI mRNA in melanoma metastases and clinical outcome

F Journe et al

1732

Sarangarajan R, Zhao Y, Babcock G, Cornelius J, Lamoreux ML, Boissy RE (2000) Mutant alleles at the brown locus encoding tyrosinase-related protein-1 (TRP-1) affect proliferation of mouse melanocytes in culture. Pigment Cell Res 13: $337-344$

Savoia P, Fava P, Nardo T, Osella-Abate S, Quaglino P, Bernengo MG (2009) Skin metastases of malignant melanoma: a clinical and prognostic survey. Melanoma Res 19: $321-326$

Schlagenhauff B, Stroebel W, Ellwanger U, Meier F, Zimmermann C, Breuninger H, Rassner G, Garbe C (1997) Metastatic melanoma of unknown primary origin shows prognostic similarities to regional metastatic melanoma: recommendations for initial staging examinations. Cancer 80: $60-65$

Soltani MH, PichardoR, Song Z, Sangha N, Camacho F, Satyamoorthy K, Sangueza OP, Setaluri V (2005) Microtubule-associated protein 2, a marker of neuronal differentiation, induces mitotic defects, inhibits growth of melanoma cells, and predicts metastatic potential of cutaneous melanoma. Am J Pathol 166: 1841 - 1850

Takechi Y, Hara I, Naftzger C, Xu Y, Houghton AN (1996) A melanosomal membrane protein is a cell surface target for melanoma therapy. Clin Cancer Res 2: $1837-1842$
Vijayasaradhi S, Doskoch PM, Wolchok J, Houghton AN (1995) Melanocyte differentiation marker gp75, the brown locus protein, can be regulated independently of tyrosinase and pigmentation. J Invest Dermatol 105: $113-119$

Wasmeier C, Romao M, Plowright L, Bennett DC, Raposo G, Seabra MC (2006) Rab38 and Rab32 control post-Golgi trafficking of melanogenic enzymes. J Cell Biol 175: $271-281$

Watabe H, Valencia JC, Yasumoto K, Kushimoto T, Ando H, Muller J, Vieira WD, Mizoguchi M, Appella E, Hearing VJ (2004) Regulation of tyrosinase processing and trafficking by organellar $\mathrm{pH}$ and by proteasome activity. J Biol Chem 279: $7971-7981$

Wellbrock C, Rana S, Paterson H, Pickersgill H, Brummelkamp T, Marais $\mathrm{R}$ (2008) Oncogenic BRAF regulates melanoma proliferation through the lineage specific factor MITF. PLoS One 3: e2734

Winnepenninckx V, Lazar V, Michiels S, Dessen P, Stas M, Alonso SR, Avril MF, Ortiz Romero PL, Robert T, Balacescu O, Eggermont AM, Lenoir G, Sarasin A, Tursz T, van den Oord JJ, Spatz A (2006) Gene expression profiling of primary cutaneous melanoma and clinical outcome. J Natl Cancer Inst 98: 472-482

This work is published under the standard license to publish agreement. After 12 months the work will become freely available and the license terms will switch to a Creative Commons Attribution-NonCommercial-Share Alike 3.0 Unported License. 